\title{
Chemosynthesis and structural characterization of a novel lignin-based bio-sorbent and its strong adsorption for $\mathrm{Pb}$ (II)
}

Wang, Bing; Wen, Jia-Long; Sun, Shao-Long; Wang, Han-Min; Wang, ShuangFei; Liu, Qiuyun; Charlton, Adam; Sun, Run-Cang

\section{Industrial Crops and Products}

\section{DOI:}

10.1016/j.indcrop.2017.06.013

Published: 01/12/2017

Peer reviewed version

Cyswllt i'r cyhoeddiad / Link to publication

Dyfyniad o'r fersiwn a gyhoeddwyd / Citation for published version (APA):

Wang, B., Wen, J-L., Sun, S-L., Wang, H-M., Wang, S-F., Liu, Q., Charlton, A., \& Sun, R-C. (2017). Chemosynthesis and structural characterization of a novel lignin-based bio-sorbent and its strong adsorption for $\mathrm{Pb}$ (II). Industrial Crops and Products, 108, 72-80.

https://doi.org/10.1016/j.indcrop.2017.06.013

\footnotetext{
Hawliau Cyffredinol / General rights

Copyright and moral rights for the publications made accessible in the public portal are retained by the authors and/or other copyright owners and it is a condition of accessing publications that users recognise and abide by the legal requirements associated with these rights.

- Users may download and print one copy of any publication from the public portal for the purpose of private study or research.

- You may not further distribute the material or use it for any profit-making activity or commercial gain

- You may freely distribute the URL identifying the publication in the public portal?
}

Take down policy

If you believe that this document breaches copyright please contact us providing details, and we will remove access to the work immediately and investigate your claim. 
2 Chemosynthesis and structural characterization of a novel

3 lignin-based bio-sorbent and its strong adsorption for $\mathrm{Pb}$ (II)

4

5 Bing Wang ${ }^{\mathrm{a}}$, Jia-Long Wen ${ }^{\mathrm{a}}$, Shao-Long Sun ${ }^{\mathrm{a}}$, Han-Min Wang ${ }^{\mathrm{a}}$, Shuang-Fei Wang ${ }^{\mathrm{b}}$,

6 Qiu-Yun Liu ${ }^{\mathrm{c}}$, Adam Charlton ${ }^{\mathrm{c}}$, Run-Cang Sun ${ }^{\mathrm{a}}$ *

7

8

9

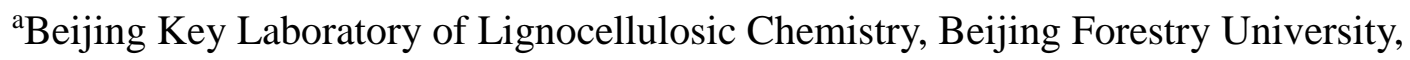
No.35 Tsinghua East Road Haidian District, 100083, Beijing, China.

bLight Industry and Food Engineering College, Guangxi University, Guangxi 530004 China.

${ }^{\mathrm{c}}$ The BioComposites Centre, Bangor University, Bangor LL57 2UW, UK.

.

5

16

7

18

19


ABSTRACT:

The removal of heavy metals ions from wastewater by an economic, high-effective, and environmentally friendly method is particularly important. In this study, an effective lignin-based bio-adsorbent (SAPL-1.5), which contained specific functional groups and spatial cross-linking structures, was synthesized through chemical modification. SAPL-1.5 was comprehensively characterized by ${ }^{31} \mathrm{P},{ }^{1} \mathrm{H},{ }^{13} \mathrm{C} \mathrm{NMR}$, and elemental analysis as compared to the raw lignin. The results showed that the chemical reactivity of lignin was significantly improved after phenolation process, and the adsorption groups were successfully grafted onto lignin macromolecule. In addition, the influences of $\mathrm{pH}, \mathrm{SAPL}-1.5$ dosage, contact time, and initial $\mathrm{Pb}$ (II) concentration on the adsorption performance was systematically investigated. The highest adsorption capacity reached to $130.2 \mathrm{mg} / \mathrm{g}$ ( $\mathrm{Pb}$ (II), $140 \mathrm{mg} / \mathrm{L}$ ), and a removal efficiency of $100 \%$ was achieved ( $\mathrm{Pb}$ (II), $20 \mathrm{mg} / \mathrm{L}$ ). Moreover, the adsorption isotherm and adsorption kinetics indicated that the results were fitting well with the Langmuir and pseudo-second-order model, respectively. Furthermore, the removal efficiency of SAPL-1.5 for $\mathrm{Pb}$ (II) $(20 \mathrm{mg} / \mathrm{mL})$ still maintained over $85 \%$ after 5 cycles. Therefore, the lignin-based material obtained could be considered as a promising potential adsorbent with a low cost, high performance and reutilization for its application in the wastewater treatment process. It is believed that the lignin-based bio-sorbent can enlarge the lignin valorization in the current biorefinery process.

To whom correspondence should be addressed. Tel: +86-10-62336903.

Fax: +86-10-62336903. E-mail:rcsun3@bjfu.edu.cn. 


\section{Introduction}

With the development of industry, water pollution induced by heavy metals such as copper, silver, cadmium, mercury, and lead has drawn great concerns (Uddin et al., 2017; Hossain et al., 2014; Lü et al., 2013).These heavy metals are non-degradable and tend to accumulate in living organisms, which will lead to ecological and human health damage. Obviously, heavy metal ions should be removed from waste water prior to discharge them into the environment. Up to now, a variety of methods, such as chemical precipitation, electro dialysis, ion exchange, and membrane separation, have been explored to remove the toxic heavy metal ions from aqueous solutions (Reddad et al., 2012; Mohan et al., 2006; Ozmen et al., 2010). However, each method has its own disadvantage, such as high cost and energy consumption, as well as the need of large quantities of chemical additives, which resulted in the formation of by-product sludge and secondary pollution. Therefore, it is necessary to develop more effective and inexpensive methods to remove heavy metals from waste water. Based on the previous reports (Bhattacharya et al., 2008; Dodsonet al., 2015; Daset al., 2010), bio-sorption is one of the most promising method as compared to others, since it was handy, economic, and high-efficiency under low metal concentrations, which is important for deep purification of waste water. Thus, an adsorbent with low-cost and high-effective derived from an abundant and sustainable material in the nature is needed.

Biomass materials, such as cellulose, hemicelluloses, lignin, bacteria, fungi, 
1 chitosan, and agricultural wastes, have many unique advantages including sustainable resource, low cost, biocompatibility, and low environmental impact. Therefore, these materials have been drawn great attention on the development of biomass adsorbents (Das et al., 2010; Guo et al., 2008). Among the biomass materials, lignin has many advantages of adsorption owing to the specific functional groups and spatial structure features (Dizhbite et al., 1999; Li et al., 2016a; Brandt et al., 2013).

Lignin, the second most abundant renewable material, which is next to cellulose in biomass, is a phenolic polymer derived primarily from three different phenylpropanoid units, such as syringyl, guaiacyl, and p-hydroxyphenol units (Ralph et al., 2010). In the worldwide pulping industry, over 70 million tons of lignin are generated as a by-product ever year. However, only $2-10 \%$ of the total lignin produced is used as high value-added materials or chemicals, and the left more than $90 \%$ is burned as low value fuels (Dodson et al., 2015). In fact, lignin is a very promising raw material available for the preparation of adsorbent, owing to its low cost and toxicity, and possession of several functional groups (methoxyl, aliphatic hydroxyl, phenolic hydroxyl, carboxyl, etc) (Mohan et al., 2006). Actually, lignin has been identified to be an adsorbent for the adsorption of heavy metal ions (Guo et al., 2008; Mohanet al., 2006; Maldhure et al., 2011; Geet al., 2014). Demirbas (Demirbaset al., 2004) developed a lignin-based adsorbent with an adsorption capacity of $8.2-9.0 \mathrm{mg} / \mathrm{g}$ for $\mathrm{Pb}$ (II) and $6.7-7.5 \mathrm{mg} / \mathrm{g}$ for $\mathrm{Cd}$ (II). The lignin obtained from enzymatic hydrolysis residues of cornstalk showed a maximum adsorption 
1 capacity of $20 \mathrm{mmol} / \mathrm{L}$ for $\mathrm{Au}$ (III) (Ge et al., 2014). However, the adsorption capacity

2 of unmodified lignin is usually limited by low quantity of functional groups, such as

3 sulfo, amino, and hydroxyl groups, therefore, modification of lignin before utilization

4 is highly necessary. To enhance lignin's adsorptive property, O, N or (and) S

5 -containing functional groups were preferred to grafted to the lignins. Generally, the

6 introduction of nitrogen- and sulphur-containing functional groups is expected to

7 enhance the redox and adsorptive property of lignins. Ge et al. (Ge et al., 2014) found

8 that the maximum adsorption capacity of lignin with functional groups, such as

9 sulfonic and amino, was as high as 45 and $53 \mathrm{mg} / \mathrm{g}$ for $\mathrm{Cu}$ (II) and $\mathrm{Pb}$ (II), respectively. Peternele et al. (Peternele et al., 1999) modified the lignins with

11 carboxymethyl groups, and the adsorption capacity reached to 80.3 and $37.9 \mathrm{mg} / \mathrm{g}$ for $\mathrm{Pb}$ (II) and Cd (II), respectively. These reports proved that the lignin can be used as an adsorbent to purify the wastewater. However, the adsorption capacity or (and) removal rate of these lignin-based biosorbents were limited, especially at low metal ion concentrations. In addition, the adsorbents could not be easily separated and recycled, which would restrict its applications in many fields and generate the secondary pollution.

To our knowledge, one of the most important reasons for the limited adsorption capacity is attributed to lower chemical reactivity of lignin from industrial and current biorefinery process, which resulted in a handful of functional groups grafted onto the lignin. To improve the chemical reactivity of the raw lignins, many approaches have 
1 been developed to enhance the chemical reactivity of lignins, mainly including

2 demethylation and phenolation (Kai et al., 2016). Phenolation is a method to

3 introduce the phenol to lignins, further introduce more phenolic hydroxyl groups into

4 lignins and the chemical reactivity of lignins can be significantly improved. These

5 lignins could be developed into novel lignin-based biomaterials, such as adsorbent,

6 antioxidant, fire retardant, and phenolic resin (Kai et al., 2016).

7

In this study, the lignin was activated through an improved process of phenolation before modification (Scheme 1a). The amino and sulfonic functional groups were then sequentially grafted onto phenolated lignin by mannich reaction and sulfomethylation, respectively (Scheme 1b). Considering the high toxicity and seriously damage to the nervous and reproductive system, kidneys, as well as liver, $\mathrm{Pb}$ (II) as a model heavy metal ion was chosen for evaluating the adsorption capacity of lignin-based adsorbent. The influences of initial concentration and $\mathrm{pH}$ of $\mathrm{Pb}$ (II), contract times, as well as reagent dosages on the adsorptive property of lignin were comprehensively investigated. The kinetic and equilibrium parameters were also calculated to investigate the adsorption performance of modified lignin.

\section{Materials and methods}

\subsection{Materials}

The alkaline lignin was obtained from the hydrothermally pretreated corn cob and provided from Shandong Longlive Bio-technology Co., Ltd, China. The general 
1 process for the lignin production has been detailed described in our previous paper

2 (Yang et al., 2014). In brief, the alkaline lignin was obtained from the hydrothermally

3 pretreated corn cob. Phenol, sulfuric acid $\left(\mathrm{H}_{2} \mathrm{SO}_{4}\right)$, 1, 6-hexanediamine (HD),

4 formaldehyde $(\mathrm{HCHO})$, sodium hydroxide $(\mathrm{NaOH})$, and carbon disulfide $\left(\mathrm{CS}_{2}\right)$ and

5 other reagents were purchased from Sigma-Aldrich (Beijing, China).

\subsection{Phenolation of lignin}

8 The lignin was activated by an improved phenolation process prior to ammonization and sulfuration (Scheme 1a). Simply, phenolation of alkaline lignin was performed with $20 \mathrm{~g}$ lignin dissolved in $40 \mathrm{~g}$ phenol solution, and the homogenous mixture was catalyzed by $\mathrm{H}_{2} \mathrm{SO}_{4}(2.18 \mathrm{~mL})$ at $110{ }^{\circ} \mathrm{C}$ for $20 \mathrm{~min}$. After

\subsection{Chemosynthesis of lignin-based biosorbent}

The ammonization and sulfuration of lignin (SAPL, SAL) were obtained through Mannich (Scheme 1a) and sulfuration (Scheme 1b) reaction. (i) 5.0 g L or PL and 10 $\mathrm{mL} 0.4 \mathrm{~mol} / \mathrm{L} \mathrm{NaOH}$ were drop into a three round bottom flask bottle. The reaction was kept at room temperature for about 15 min with vigorously stirring to ensure the 
1

complete dissolution of lignin. Subsequently, a certain amount of formaldehyde, HD, and deionized water (Table S1) were added into the flask to form a $100 \mathrm{~mL}$ solution with continuous stirring. After that, the reaction temperature was elevated to $60{ }^{\circ} \mathrm{C}$, and the time lasted for $3 \mathrm{~h}$. (ii) sulfuration: the resulting mixture was cooled down to $40{ }^{\circ} \mathrm{C}$, and a certain amount of carbon disulfide (Table S1) was slowly added into the solution drop, and then kept for $4 \mathrm{~h}$ to complete the sulfuration. At the end of the designated time, the mixture was dialyzed with dialysis bag $(M w=1000)$. After that, all the modified lignins were freeze-dried and then stored indifferent centrifuge tubes for the characterization and adsorption. The detailed formula of fraction of lignin-based biosorbent was listed in Table S1.

\subsection{Characterizations}

In this study, elemental analysis $(\mathrm{C}, \mathrm{H}, \mathrm{N}$ and $\mathrm{S})$ of the lignins was measured by $\mathrm{PE}$ 2400 II. NMR spectra $\left({ }^{1} \mathrm{H},{ }^{13} \mathrm{C}, 2 \mathrm{D}-\mathrm{HSQC}\right.$, and ${ }^{31} \mathrm{P}$ NMR spectra) were performed on a Bruker AVIII (400 M) according to previous publications (Ralph et al., 2010; Pu et al., 2011; Wen et al., 2013; Sun et al., 2013).

\subsection{Batch adsorption}

All the adsorption tests were performed at $25{ }^{\circ} \mathrm{C}$ to investigate the adsorptive property of the modified lignins for the $\mathrm{Pb}$ (II). The aqueous solution of the metal ions was prepared by dissolving $\mathrm{Pb}\left(\mathrm{NO}_{3}\right)_{2}$ in deionized water for different concentrations. Typically, a certain amount of SPAL-1.5 was dispersed in a $\mathrm{Pb}\left(\mathrm{NO}_{3}\right)_{2}$ aqueous 
1 solution $(50 \mathrm{~mL})$. Then, the mixture was incubated in water bath at $25{ }^{\circ} \mathrm{C}$ with

2 constant stirring for given time. As the predetermined time arrived, $5 \mathrm{~mL}$ supernatant

3 solutions were pipetted and then filtered through $0.22 \mathrm{~mm}$ membranes for the

4 detection of $\mathrm{Pb}$ (II). The concentrations of the initial and residual ions were

5 determined by inductively coupled plasma (ICP) spectrometer (ICP-8000,

6 PerkinElmer), respectively. In this study, the factors affect the adsorption capacity (Qe)

7 and removal efficiency ( $\mathrm{R}, \%$ ) for $\mathrm{Pb}$ (II) including the $\mathrm{pH}$, initial concentration of the

$8 \mathrm{~Pb}$ (II) aqueous solution, lignin dosage, as well as the contact time of SAPL-1.5 in

$9 \mathrm{~Pb}\left(\mathrm{NO}_{3}\right)_{2}$ aqueous solution were thoroughly investigated. In addition, the $\mathrm{pH}$ of

$10 \mathrm{~Pb}\left(\mathrm{NO}_{3}\right)_{2}$ aqueous solution was adjusted by $0.1 \mathrm{M} \mathrm{HNO}_{3}$ and $\mathrm{NaOH}$. The removal

11 efficiency (formula 1) and adsorption capacity (formula 2) were calculated based on

12 the following equations:

$13 \quad R=\frac{C_{0}-C_{e}}{C_{0}} \times \mathbf{1 0 0 \%}$

$14 \quad \mathbf{Q}_{\mathrm{e}}=\frac{\mathrm{C}_{0}-\mathrm{Ce}}{\mathrm{m}} \times \mathbf{V}$

15 where $\mathrm{R}$ and $\mathrm{Q}_{\mathrm{e}}$ represent the removal efficiency (\%) and adsorption capacity at equilibrium (mg/g), respectively. $\mathrm{C}_{0}$ and $\mathrm{C}_{\mathrm{e}}$ are the initial and equilibrium concentrations of metal ions (mg/L); V is the volume of the $\mathrm{Pb}$ (II) solutions (L), and $\mathrm{m}$ is the dry weight of SAPL-1.5 (g). All experiments were performed in duplicate and the results presented in the manuscript were the mean values.

\subsection{Regeneration of SAPL-1.5}

To investigate the reusability of SAPL-1.5, regeneration experiment was conducted 
1 in the current study. In brief, the metallic-loaded SAPL-1.5 was transferred into $0.1 \mathrm{M}$

$2 \mathrm{HNO}_{3}$ aqueous solution $(100 \mathrm{~mL})$ with stirring for $120 \mathrm{~min}$ at room temperature. The

3 insoluble solids were filtered and washed with distilled water and then poured into 0.1

$4 \mathrm{M} \mathrm{NaOH}$ aqueous solution $(100 \mathrm{~mL})$ with stirring for $120 \mathrm{~min}$ at room temperature.

\section{Results and discussion}

\subsection{Characterization of lignins with or without modification}

${ }^{31} \mathrm{P}$ NMR spectroscopy is a facile and direct analysis tool for quantifying the different hydroxyl groups (carboxyl groups, phenolic hydroxyl, and aliphatic hydroxyl) in lignin (Pu et al., 2011; Granata et al., 1995). Generally, the content of active sites was related to the type of lignins because G- and H-type lignins contain one and double active sites, respectively. Therefore, in this study, the changes of varios hydroxyl groups in these lignins were measured by ${ }^{31} \mathrm{P}-\mathrm{NMR}$ spectra (Figure1 and Table 1). As shown in Figure 1, the intensity of the signals at 138.4-137.1 ppm referring to $p$-hydroxyphenyl units was significantly increased as compared to that of L, implying that the phenol was successfully grafted onto the lignin. By contrast, the intensity of the signals belonging to aliphatic hydroxyl groups (Al-OH) in PL (146.0-149.0 ppm) was observably reduced. In addition, the quantitative data inTable 1 showed the distribution of the varied hydroxyl groups $(\mathrm{Al}-\mathrm{OH}, \mathrm{S}-\mathrm{OH}, \mathrm{G}-\mathrm{OH}, \mathrm{H}-\mathrm{OH}$, and $-\mathrm{COOH}$ ) and active sites of the lignins. The content of Al-OH was decreased to $0.24 \mathrm{mmol} / \mathrm{g}$ in $\mathrm{PL}$ from $1.48 \mathrm{mmol} / \mathrm{g}$ in $\mathrm{L}$, which is probably that the phenolation reaction occurred in the side-chain of lignin under the acidic conditions. Furthermore, 
1 the increased content of condensed syringyl (5-substituted, 144.5-143.2 ppm)

2 phenolic moieties $(0.23$ to $0.25 \mathrm{mmol} / \mathrm{g})$ is attributed to the occurrence of a minimal

3 amount of condensation reaction. Actually, the condensation reaction could be also

4 reflected by the slightly increase of molecular weight (FigureS1). Furthermore, the

5 decreased of G-type $\mathrm{OH}$ groups content $(1.16-0.98 \mathrm{mmol} / \mathrm{g})$ implied that the

6 demethylation and condensation reaction occurred during the phenolation process. It

7 should be noted that the content of $\mathrm{H}$-type $\mathrm{OH}$ was increased from 0.68 (L) to 3.14

$8 \mathrm{mmol} / \mathrm{g}$ (PL), suggesting that the phenol was successfully grafted onto lignin.

9 Especially, the results showed that the content of active sites in PL was three times

higher than those in L. Therefore, it could be concluded that the chemical reactivity of lignin was significantly improved after phenolation, which would be beneficial for the chemical modification of raw lignin.

Subsequent 2D-HSQC spectra of lignin and phenolated lignin (Figure S2) also provide some evidences for the successful phenolation of lignin in the present study. As compared to the spectrum of $\mathrm{L}$, only small correlated signals for $\beta-O-4$ linkages were disappeared in the spectrum of PL. In fact, the intensity of the signals appearing in the spectrum of $\mathrm{L}$ was weaken as compared with that of PL, which was attributed to the low content of $\mathrm{C}_{9}$-units in PL. Referring to the aromatic region of the $\mathrm{L}$ and PL, it was found that no obvious changes of the signals for $S$ and $G$ units occurred expected for the disappeared signals for dissociative $p$-coumric acid ( $p$-CA). This suggested that the dissociative $p$-coumric acid, which was coprecipitated with the alkaline lignin, 
was removed after phenolation process. Besides, the enlarged signals for H-type lignin units indicated of successful phenolation of phenol onto lignin. Considering the unchanged signals for $\mathrm{S}$ and $\mathrm{G}$ units as well as the reduced aliphatic $\mathrm{OH}$ groups in the PL, it was speculated that the phenolation was mainly condensed with the side-chain of the lignin rather than aromatic rings in the present study.

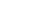

In the ${ }^{1} \mathrm{H}$ NMR spectrum of phenolated lignin, large amplification of the peak belonging to aromatic protons (6.0-7.4 ppm) could be detected (Figure 2). It was observed that the intensity of aromatic protons was increased in PL as compared to that in L, suggesting that the phenol was successfully grafted onto lignins, which was in accordance with the results of the above ${ }^{31} \mathrm{P}$ NMR, 2D-HSQC, and the following ${ }^{13} \mathrm{C}$ NMR spectra. However, the intensity of signals (3.4-3.9 ppm) assigned to $\alpha$ and $\gamma-\mathrm{H}$ was decreased in PL, implying that the phenolization appeared in the side chain of lignin as illustrated in scheme 1a, which was proved by $2 \mathrm{D}-\mathrm{HSQC}$ and ${ }^{31} \mathrm{P}-\mathrm{NMR}$ spectra. However, it was found that the $\mathrm{HCHO}$ replaced the aromatic protons through mannich reaction, which resulted in the decrease of the aromatic signals (6.0-7.4 ppm) intensity in APL-1.5 and SAPL-1.5. Furthermore, it should be noted that the newly appeared signals at 1.46 and $2.75 \mathrm{ppm}$ are assigned to the $\mathrm{H}$ of the introduced $\mathrm{HD}$ in SAPL-1.5, implying that the HD was successfully grafted onto lignin.

To further investigate the mechanism of the chemical modification of lignin, ${ }^{13} \mathrm{C}$ NMR spectra of lignins and its derivatives (L, PL, and SAPL-1.5) were performed, 
1 and the results are given in Figures 3 and S3. The detail assignments of the lignin

2 could be achieved according to the previous publications of the NMR characterization

3 of lignins (Ralph et al., 2010; Sun et al., 2013). In the aromatic regions (153-103 ppm)

4 of the three samples, the S-type units are detected at 152.3, 147.6, 138.3, and 104.4

5 ppm, derived from etherified $S_{3,5}$, non-etherified $S_{3,5}$, etherified $S_{4}$, and $S_{2,6}$,

6 respectively. In addition, the G-type units give signals at $148.3 \mathrm{ppm}$ (C-3, etherified),

$7 \quad 147.5 \mathrm{ppm}$ (C-4, etherified), $144.3 \mathrm{ppm}$ (C-4, non-etherified), 135.9 ppm (C-1,

8 etherified), and $118.9 \mathrm{ppm}(\mathrm{C}-5)$. Apart from the signals represented for the $\mathrm{S}$ and $\mathrm{G}$

9 units, the $\mathrm{H}$ unit was also clearly distinguished according to the previous publications

10 (Ralph et al., 2010; Sun et al., 2013).Furthermore, an obvious signal belonging to the

$11 \mathrm{C}-8$ of dissociated $p$-coumaric acid ( $p$-CA) appeared at $168.1 \mathrm{ppm}$ in the spectrum of

12 lignin (Sun et al., 2013.Cui et al., 2011). After the phenolation, it was found that the

13 signal for dissociated $p$-CAwas disappeared, suggesting that the lignin was purified

14 during the phenolation process. In addition, it was observed that the intensity of the

15 signal at $128.2 \mathrm{ppm}$ assigned to $\mathrm{H}_{2,6}$ was obviously increased. However, the signal of

$\mathrm{H}_{2,6}$ was shifted upfield and the intensity was then decreased due to the substitution of

$\mathrm{H}_{2,6}$ during the mannich reaction. Meanwhile, the decreased intensity of $\mathrm{G}_{5}$ signal in

SAPL-1.5 also verified the occurrence of the substitution reaction at $\mathrm{G}_{5}$ position.

Moreover, considering the newly appearance signals attached to the carbon of $\mathrm{CH}_{2}$ the following elemental analysis. 
2 Elemental analysis (Table 2) was performed to investigate the quantitative changes

3 of the $\mathrm{C}, \mathrm{H}, \mathrm{N}$, and $\mathrm{S}$ contents in lignins, which were affected by the different molar

4 ratios among $\mathrm{L}, \mathrm{HCHO}, \mathrm{HD}$, and $\mathrm{CS}_{2}$, as well as the phenolation. The results showed

5 that the content of $\mathrm{N}$ and $\mathrm{S}$ was elevated with the increment of the molar ratios

6 between lignin and reactants $\left(\mathrm{HCHO}, \mathrm{HD}\right.$, and $\left.\mathrm{CS}_{2}\right)$. As compared to SAL-1.5, the

7 content of C in SAPL-1.5 significantly declined. However, the S and N contents were

8 obviously enhanced to 8.38 and $11.98 \%$, respectively. Therefore, it could be

9 concluded that the chemical reactivity was enhanced by phenolation and resulted in

more $\mathrm{CS}_{2}$ were grafted onto lignin, which would provide abundant adsorption sites for the adsorption of metal ions. In this study, considering the economic value, SPAL-1.5 instead of SAPL-2 was chosen for investigating the adsorption property of $\mathrm{Pb}$ (II) in the following experiment.

\subsection{Adsorption of $\mathrm{Pb}(\mathrm{II})$}

\subsubsection{Effect of the initial $p H$}

The initial $\mathrm{pH}$ value of metal ions aqueous solution is a critical factor in influencing the adsorption performances, since it affected the surface charge of SAPL-1.5, the degree of ionization, and speciation of adsorbate (Ge et al., 2014). In this study, the adsorption capacity of $\mathrm{Pb}$ (II) by SAPL-1.5 was performed with the $\mathrm{pH}$ between 2.0 and 6.0. In addition, the initial $\mathrm{Pb}$ (II) concentration was $20 \mathrm{mg} / \mathrm{L}$, and the constant time maintained $90 \mathrm{~min}$. As shown in Figure 4a, the adsorption capacity enhanced 
1 with the increase of $\mathrm{pH}$, and reached to the maximum value when the $\mathrm{pH}$ was 5.0. The

2 reason for the limited adsorption capacity at low $\mathrm{pH}$ was that the strong competition

3 for the adsorption sites of lignins would occurred between the constant $\mathrm{Pb}$ (II) ions

4 andthe high $\mathrm{H}^{+}$ions ( $\mathrm{Li}$ et al., 2016b; Mahmoud et al., 2015). However, as the $\mathrm{pH}$

5 enhanced, the declined $\mathrm{H}^{+}$ions would weaken the competition, and consequently

6 enhanced the metallic ions uptake. However, too higher $\mathrm{pH}$ of the solution would

7 resulted in the secondary reaction productions, such as $\mathrm{Pb}(\mathrm{OH})_{2}$ and $\mathrm{Pb}(\mathrm{OH})_{4}{ }^{2-}$,

8 which could affect the adsorption process and reduced the adsorption capacity.

9 Actually, the $\mathrm{Pb}$ (II) adsorption process was divided into three stages based on the different pH conditions (Yang et al., 2011a; Yang et al., 2011b; Dlamini et al., 2012). In detail, precipitation or hydrolyses began to appear as the $\mathrm{pH}$ was higher than 6.0 , surficial deposition occurred when the $\mathrm{pH}$ decreased to 5.0 from 6.0, and competitive adsorption between $\mathrm{H}_{3} \mathrm{O}^{+}$and $\mathrm{Pb}$ (II) appeared as the $\mathrm{pH}$ further reduce to 5.0. The hydrolysis reaction of $\mathrm{Pb}$ (II) is described in equation 3 and 4.

$\mathrm{Pb}^{2+}+2 \mathrm{OH}^{-} \rightarrow \mathrm{Pb}(\mathrm{OH})_{2}$

$\mathrm{Pb}(\mathrm{OH})_{2}+2 \mathrm{OH}^{-} \rightarrow \mathrm{Pb}(\mathrm{OH})^{2^{-}}$

The zeta potential of lignin is also an important parameter to evaluate the absorbability. As shown in Figure 4b, the zeta potential decreased with the increase of $\mathrm{pH}$, and the zero charge of SAPL-1.5 appeared at $\mathrm{pH}$ 3.0. With the $\mathrm{pH}$ further decreased to 5.0, the negative charges reached to 20.5 , which was significantly higher than those of other chemical modification lignins that have been previously reported (Ge et al., 2014; Li et al., 2015). Furthermore, the more negatively charged surfaces of 
1 SAPL-1.5 at higher $\mathrm{pH}$ value would providemore stable environment for lignin-based

2 adsorbent. Therefore, for acquiring the highest adsorption capacity of heavy metals

3 and avoiding the occurrence of precipitation of $\mathrm{Pb}(\mathrm{OH})_{2}$ and $\mathrm{Pb}(\mathrm{OH})_{4} 4^{2-}$, the batch

4 adsorption experiment of $\mathrm{Pb}$ (II) was performed at $\mathrm{pH}$ value of 5.0.

\subsubsection{Effect of SAPL-1.5 dosages}

7 In this study, the effect of SAPL-1.5 dosages on the adsorption capacity and 8 removal efficiency was performed at $\mathrm{pH} 5.0$ with an initial ion concentration of 20

$9 \mathrm{mg} / \mathrm{L}$ at a temperature of $25^{\circ} \mathrm{C}$ for a contact time of $40 \mathrm{~min}$, and the results are given in Figure 5. In low dosages, it showed the high adsorption capacity, which was mainly due to the increased ratio of the adsorbent to metal ions. However, it was observed that the adsorption capacity decreased with increase of SAPL-1.5 dosages. This could be explained by the generation of substantial unsaturated adsorption sites which resulted from the higher SAPL-1.5 dosages. By contrast, the removal efficiency of $\mathrm{Pb}$ maximum value $(100 \%)$ at a dosage of $0.03 \mathrm{~g} / 50 \mathrm{~mL}$. The reason for the increase of removal efficiency was probably attributed to the additional adsorption sites and the contact area that provided by the higher SPAL-1.5 content, while the number of metal ions was kept constant under a low concentration of $\mathrm{Pb}$ (II) (20 mg/L) (Bansal et al., 2009; Li et al., 2015). 
To evaluate the adsorption capacity of SPAL-1.5 for lead ions, adsorption isotherms were measured with the initial lead concentrations of $20-160 \mathrm{mg} / \mathrm{L}$ at a $\mathrm{pH}$ of 5.0 , for an SAPL-1.5 dosage of $0.03 \mathrm{~g} / 50 \mathrm{~mL}$, at a temperature of $25^{\circ} \mathrm{C}$, and a contact time of $90 \mathrm{~min}$. As can be seen from Figure 6a, the adsorption capacity (calculated as formula 3) increased with the increase of initial $\mathrm{Pb}$ (II) concentration, and the maximum adsorption capacity reached to over $130 \mathrm{mg} / \mathrm{g}$, which was obviously higher than those of other lignins presented in Table 3. The reason for the elevated adsorption capacity was that the higher lead concentration would provide more contracting surface of $\mathrm{Pb}$ (II) to SAPL-1.5. However, the adsorption capacity began to flatten as the initial lead concentrations reached to $140 \mathrm{mg} / \mathrm{L}$. This was that the limited adsorption sites were sufficiently occupied by an excess of $\mathrm{Pb}$ (II) ions, and then resulted in polymer chain shrinking (Pehlivan et al., 2006). In addition, the Langmuir and Freundlich isotherm models were used to fit the adsorption data in this study, respectively (Figure6b). The two isotherm models has be described in supporting information (Formula S1 and S2). As shown in Figure $6 \mathrm{~b}$ and Table 4, the adsorption capacity for $\mathrm{Pb}$ (II) is in good agreement with the Langmuir adsorption model $\left(\mathrm{R}_{1}^{2}=0.9940\right)$ rather than Freundlich model $\left(\mathrm{R}_{2}{ }^{2}=0.9677\right)$. The adsorption capacity $\left(\mathrm{Q}_{\mathrm{m}}=130.2 \mathrm{mg} / \mathrm{g}\right)$ was closed to the maximum adsorption $\left(\mathrm{Q}_{\mathrm{e}}=136.9 \mathrm{mg} / \mathrm{g}\right)$, suggesting that the adsorption behavior of SAPL-1.5 occurred on the surface is homogeneous and that the adsorption can be characterized as monolayer manner (Langmuir et al., 1918). 
2 The contact time between SAPL-1.5 and $\mathrm{Pb}$ (II) is also a vitally important

\subsubsection{Effect of contact time}

parameter for evaluating the adsorption properties of adsorbents. To determine an optimum contact time between SAPL-1.5 and $\mathrm{Pb}$ (II) ions, the adsorption process was completed under the condition of a $\mathrm{Pb}$ (II) concentration of $80 \mathrm{mg} / \mathrm{L}$, a dosage of 0.03 g, a temperature of $25^{\circ} \mathrm{C}$, and a $\mathrm{pH}$ of 5.0. Meanwhile, the samples were collected every 10 mins for 8 times. As shown in Figure 7, the adsorbing capacity rapidly increased within the initial 10 mins, and then the growth rate became slow and finally flatten in $40 \mathrm{~min}$. The fast adsorption could be ascribed to the large number of effective adsorption sites on the surface of SAPL-1.5 (Ge et al., 2014; Songet a., 2015; Say et al., 2008; Cui et al., 2015). In detail, the good dispersibility of SAPL-1.5 and high-efficiency chelating ability of $\mathrm{C}^{-\mathrm{S}^{-}}$towards metallic ions is the most important reason. Besides, the electrostatic attraction of hydroxyl groups (original and grafted hydroxyl groups, as well as carboxyl groups) were probably another important reason for the rapid adsorption (Aboutalebi et al., 2011; Karnitz et al., 2007)

In this study, the adsorption kinetics was examined through the calculation of pseudo-first-order and pseudo-second-order model. The two kinetic rate equations has be described in supporting information (Formula S3 and S4). The fitting results are presented in Figure7 and Table 5. In this study, a particular high correlation coefficient $\left(\mathrm{R}_{2}^{2}>0.9978\right)$ between $\mathrm{t}$ and $\mathrm{t} / \mathrm{Q}_{\mathrm{t}}$ implied that the pseudo-second-order model was more suitable for adsorption description. Thus, it can be concluded that the adsorption process of SAPL-1.5 is primarily due to chemisorption, such as, ion 
exchange, chelation electrostatic forces and valence forces.

\subsubsection{The reusability of SAPL-1.5}

The reusability of the adsorbent plays an important role in evaluating the potential commercialization of the adsorbent. Thus, the adsorption-desorption ability of SAPL-1.5 was realized through $0.1 \mathrm{M} \mathrm{HNO}_{3}$ and $\mathrm{NaOH}$ aqueous solution according to the description of methods section, and the results were presented in FigureS4. It was found that the removal efficiency for $\mathrm{Pb}$ (II) $(20 \mathrm{mg} / \mathrm{mL})$ still maintained above $85 \%$ after 5 cycles, and the average removal efficiency for $\mathrm{Pb}$ (II) $(20 \mathrm{mg} / \mathrm{mL}$ ) reached to $93.9 \%$. In short, all these results demonstrated that the SAPL-1.5 is a promising bio-sorbent in reducing pollution of $\mathrm{Pb}$ (II) ions for waste water treatment.

\section{Conclusion}

An effective bio-adsorbent (SAPL-1.5) was synthesized and fabricated from the renewable resource-lignin. The fundamental chemistry and adsorptive behaviors were systematically investigated. SAPL-1.5 exhibited excellent adsorption performance for $\mathrm{Pb}$ (II), which is mainly attributed to the strong electrostatic attraction between heavy metal ions and sulfuric and oxygenic functional groups. The results showed that the maximum adsorption capacity and removal efficiency of the SAPL-1.5 reached to $130.2 \mathrm{mg} / \mathrm{g}$ and $100 \%$ for $\mathrm{Pb}$ (II), respectively. In addition, the adsorption kinetics and adsorption isotherm were fitted well with the Langmuir model and pseudo-second-order. Furthermore, the adsorbent of SAPL-1.5 presented outstanding 
1 cycling capability. Considering the potential economic and eco-friendly alternative for

2 heavy metal removal, it can be concluded that SAPL-1.5 would become a promising

3 bio-adsorbent for water purification. More importantly, the present study owns good

4 scientific merit, which not only provides the theoretical foundation for lignin

5 valorization in biosorption process, but also extends the further application of lignin

6 in current biorefinery scheme.

\section{Acknowledgements}

The authors wish to express their gratitude for the financial support from National

Natural Science Foundation of China (31430092; 31500486), Fundamental Research Funds for the Central Universities (2015ZCQ-CL-02), Program of International S \& T Cooperation of China (2015DFG31860), and 111 project.

\section{Reference}

Aboutalebi, S. H., Chidembo, A. T., Salari, M., Konstantinov, K., 2011. Wexler, D. Liu, H. K.; Dou, S. X.; Comparison of GO, GO/MWCNTs composite and MWCNTs as potential electrode materials for supercapacitors. Energy Environ. Sci. 4, 1855-1865.

Brandt, A., Gräsvik, J., Hallett, J. P., Welton, T., 2013. Deconstruction of lignocellulosic biomass with ionic liquids. Green Chem. 15, 550-583.

Bansal, M., Garg, U., Singh, D., Garg, V. K., 2009. Removal of Cr (VI) from aqueous solutions using pre-consumer processing agricultural waste: A case study of rice husk. J. Hazard. Mater. 162, 312-320.

Bhattacharya A.K., Naiya, T.K.,Mandal, S.N., Das, S.K.,2008. Adsorption, kinetics 
and equilibrium studies on removal of $\mathrm{Cr}$ (VI) from aqueous solutions using different low-cost adsorbents, Chem. Eng. J. 137529-541.

Cui, L., Wang, Y., Gao, L., Hu, L., Yan, L., Wei, Q., Du, B., 2015. EDTA functionalized magnetic graphene oxide for removal of $\mathrm{Pb}$ (II), $\mathrm{Hg}$ (II) and $\mathrm{Cu}$ (II) in water treatment: Adsorption mechanism and separation property. Chem. Eng. J. 281, 1-10.

Demirbas, A., 2004. Adsorption of lead and cadmium ions in aqueous solutions onto modified lignin from alkali glycerol delignication. J. Hazard. Mater. 109, $221-226$.

Das, N., 2010. Recovery of precious metals through biosorption-a review. Hydrometallurgy 103, 180-189.

Dlamini, D. S., Mishra, A. K., Mamba, B. B., 2012. Kinetic and equilibrium studies of the removal of $\mathrm{Pb}^{2+}$ from aqueous solutions using $\mathrm{Na}_{2} \mathrm{SO}_{4}-\mathrm{EVA} / \mathrm{Cloisite}{ }^{\circledR} 20 \mathrm{~A}$ composite. Mater. Chem. Phys. 133, 369-375.

Dodson, J. R., Parker, H. L., García, A. M., Hicken, A., Asemave, K., Farmer, T.J., Hunt, A.J., 2015. Bio-derived materials as a green route for precious \& critical metal recovery and re-use. Green Chem. 17, 1951-1965.

Dizhbite, T., Zakis, G., Kizima, A., Lazareva, E., Rossinskaya, G., Jurkjane, V., Viesturs, U., 1999. Lignin-a useful bioresource for the production of sorption-active materials. Bioresource Technol. 67, 221-228.

Granata, A., Argyropoulos, D. S., 1995. 2-Chloro-4, 4, 5, 5-tetramethyl-1, 3, 2-dioxaphospholane, a reagent for the accurate determination of the uncondensed and condensed phenolic moieties in lignins. J. Agr. Chem. 43, 1538-1544.

Ge, Y., Li, Z., Kong, Y., Song, Q., Wang, K., 2014. Heavy metal ions retention by bi-functionalized lignin: Synthesis, applications, and adsorption mechanisms. J. Ind. Eng. Chem. 20, 4429-4436.

Ge, Y., Xiao, D., Li, Z., Cui, X., 2014. Dithiocarbamate functionalized lignin for efficient removal of metallic ions and the usage of the metal-loaded bio-sorbents as potential free radical scavengers. J. Mater. Chem. A. 2, 2136-2145.

Guo, X., Zhang, S., Shan, X., 2008. Adsorption of metal ions on lignin. J. Hazard. 
Mater. 151, 134-142.

He, Z. W., He, L. H., Yang, J., Lü, Q. F., 2013. Removal and recovery of Au (III) from aqueous solution using a low-cost lignin-based biosorbent. Ind. Eng. Chem. Res. 52, 4103-4108.

Hossain, M. A., Ngo, H. H., Guo, W. S., Nghiem, L. D., Hai, F. I., Vigneswaran, S., Nguyen, T. V., 2014. Competitive adsorption of metals on cabbage waste from multi-metal solutions. Bioresource Technol. 160, 79-88.

Karnitz, O., Gurgel, L. V. A., De Melo, J. C. P., Botaro, V. R., Melo, T. M. S., de Freitas Gil, R. P., Gil, L. F., 2007. Adsorption of heavy metal ion from aqueous single metal solution by chemically modified sugarcane bagasse. Bioresource Technol. 98, 1291-1297.

Kai, D., Tan, M. J., Chee, P. L., Chua, Y. K., Yap, Y. L., Loh, X. J., 2006. Towards lignin-based functional materials in a sustainable world. Green Chem. 18, 1175-1200.

Langmuir, I., 1918. The Adsorption of gases on plane surfaces of glass, mica and platinum. J. Am. Chem. Soc. 40, 1361-1403.

Li, R., Gao, B., Sun, S., Yue, Q., Li, M., Yang, X., Jia, R., 2015. Amine-cross-linked lignin-based polymer: modification, characterization, and flocculating performance in humic acid coagulation. ACS Sustain. Chem. Eng. 3, 3253-3261.

Lü, Q. F., Luo, J. J., Lin, T. T., Zhang, Y. Z., 2013. Novel lignin-poly (N-methylaniline) composite sorbent for silver ion removal and recovery. ACS Sustain. Chem. Eng. 2, 465-471.

Li, Y., Wu, M., Wang, B., Wu, Y., Ma, M., Zhang, X., 2016a. Synthesis of magnetic lignin-based hollow microspheres: a highly adsorptive and reusable adsorbent derived from renewable resources. ACS Sustain. Chem. Eng. 4, 5523-5532.

Li, F. F., Wang, X. L., Yuan, T. Q., Sun, R. C., 2016b. A lignosulfonate-modified graphene hydrogel with ultrahigh adsorption capacity for $\mathrm{Pb}$ (ii) removal. $\mathrm{J}$. Mater. Chem. A. 4, 11888-11896.

Li, Z., Xiao, D., Ge, Y., Koehler, S., 2015. Surface-functionalized porous lignin for fast and efficient lead removal from aqueous solution. ACS Appl. Materials and 
Inter. 7, 15000-15009.

Mahmoud, M. E., Abdou, A. E., Ahmed, S. B., 2015. Conversion of waste styrofoam into engineered adsorbents for efficient removal of cadmium, lead and mercury from water. ACS Sustain. Chem. Eng. 4, 819-827.

Moore, B. A., Duncan, J. R., Burgess, J. E., 2008. Fungal bioaccumulation of copper, nickel, gold and platinum. Miner. Eng. 21, 55-60.

Maldhure, A. V., Ekhe, J. D., 2011. Preparation and characterizations of microwave assisted activated carbons from industrial waste lignin for $\mathrm{Cu}$ (II) sorption. Chem. Eng. J. 168, 1103-1111.

Mohan, D., Pittman Jr, C. U., 2006. Activated carbons and low cost adsorbents for remediation of tri- and hexavalent chromium from water. J. Hazard. Mater. B. $137,762-811$.

Mohan, D., Pittman, C. U., Steele, P. H., 2006. Single, binary and multi-component adsorption of copper and cadmium from aqueous solutions on Kraft lignin-a biosorbent. J. Colloid Interf. Sci. 297, 489-504.

Ozmen, M., Can, K., Arslan, G., Tor, A., Cengeloglu, Y., Ersoz, M., 2010. Adsorption of $\mathrm{Cu}$ (II) from aqueous solution by using modified $\mathrm{Fe} 3 \mathrm{O} 4$ magnetic nanoparticles. Desalination. 254, 162-169.

Pehlivan, E., Altun, T., 2006. The study of various parameters affecting the ion exchange of $\mathrm{Cu} 2+, \mathrm{Zn} 2+, \mathrm{Ni} 2+, \mathrm{Cd} 2+$, and $\mathrm{Pb} 2+$ from aqueous solution on Dowex 50W synthetic resin. J. Hazard. Mater. 134, 149-156

Pu, Y., Cao, S., Ragauskas, A. J., 2011. Application of quantitative 31P NMR in biomass lignin and biofuel precursors characterization. Energ. Environ. Sci. 4, 3154-3166.

Peternele, W. S., Winkler-Hechenleitner, A. A., Pineda, E. A. G., 1999. Adsorption of $\mathrm{Cd}$ (II) and $\mathrm{Pb}$ (II) onto functionalized formic lignin from sugar cane bagasse. Bioresource Technol. 68, 95-100.

Reddad, Z., Gerente, C., Andres, Y., Le Cloirec, P., 2002. Adsorption of several metal ions onto a low-cost biosorbent: kinetic and equilibrium studies. Environ. Sci. Technol. 36, 2067-2073. 
Ralph, J., Landucci, L. L., 2010. NMR of lignins. CRC Press. 137-244.

Say, R., Birlik, E., Erdemgil, Z., Denizli, A., Ersöz, A., 2008. Removal of mercury species with dithiocarbamate-anchored polymer/organosmectite composites. J. Hazard. Mater. 150, 560-564.

Song, Z. X., Li, W., Liu, W.T., Yang, Y., Wang, N. N., Wang, H. J., Gao, H. Y., 2015. Novel magnetic lignin composite sorbent for chromium (VI) adsorption. RSC. Adv. 5, 13028-13035.

Sun, S. L., Wen, J. L., Ma, M. G., Li, M. F., Sun, R.C., 2013. Revealing the structural inhomogeneity of lignins from sweet sorghum stem by successive alkali extractions. J. Agr. Chem. 61, 4226-4235.

Uddin M.K., 2017. A review on the adsorption of heavy metals by clay minerals, with special focus on the past decade, Chem. Eng. J. 308, 438-462.

Wen, J. L., Sun, S. L., Xue, B. L., Sun, R. C., 2013. Recent advances in characterization of lignin polymer by solution-state nuclear magnetic resonance (NMR) methodology. Materials. 6, 359-391.

Yang, S., Hu, J., Chen, C., Shao, D., Wang, X., 2011. Mutual effects of Pb (II) and humic acid adsorption on multiwalled carbon nanotubes/polyacrylamide composites from aqueous solutions. Environ. Sci. Technol. 45, 3621-3627.

Yang, S., Wen, J. L., Yuan, T. Q., Sun, R. C., 2014. Characterization and phenolation of biorefinery technical lignins for lignin-phenol-formaldehyde resin adhesive synthesis. RSC Adv. 4, 57996-58004.

Yang, X., Yang, S., Yang, S., Hu, J., Tan, X., Wang, X., 2011. Effect of pH, ionic strength and temperature on sorption of $\mathrm{Pb}$ (II) on NKF-6 zeolite studied by batch technique. Chem. Eng. J. 168, 86-93. 